\title{
Ação antibacteriana de cimentos resinosos sobre micro-organismos do biofilme dental
}

\section{Antibacterial action of resin cements on microorganisms of dental biofilm}

Viviane Maria Gonçalves de Figueiredo* Késia de Macedo R. Farias Leite**

Rosenês Lima dos Santos ${ }^{* * *}$

Maria Regina Macedo Costa ${ }^{* * * *}$

Maria do Socorro Vieira ${ }^{* * * * *}$

\section{Resumo}

Objetivo: objetivou-se analisar a ação antibacteriana de cimentos resinosos duais sobre micro-organismos do biofilme dental. Materiais e método: foram selecionados três cimentos resinosos (Panavia ${ }^{\circledR}$ F2.0, Fill Magic Dual Cement ${ }^{\circledast}$ e Enforce $^{\circledR}$ ) além das linhagens bacterianas de Streptococcus mutans, Streptococcus sanguis, Streptococcus sobrinus e Lactobacillus casei. O teste de difusão em ágar, por meio das técnicas do poço e da superfície, foi utilizado com os cimentos no estado fresco e fotopolimerizado. Após 24 horas de incubação, foram realizadas as leituras dos halos de inibição. Resultados: o cimento Panavi ${ }^{\circledast}$ F2.0 produziu halos de inibição sobre todas as linhagens bacterianas, independente do estado ou da técnica empregada. O Fill Magic Dual Cement ${ }^{\circledR}$, no estado fresco, apresentou ação antibacteriana sobre todas as linhagens estudadas, no entanto, no estado fotopolimerizado, produziu ação antibacteriana apenas sobre as linhagens $S$. sanguis e L. casei. Já o cimento resinoso Enforce ${ }^{\circledast}$ não produziu halos sobre nenhuma linhagem bacteriana. Conclusão: o Panavi ${ }^{\circledR}$ F2.0 foi o cimento resinoso que apresentou maior ação antibacteriana, seguido do Fill Magic Dual Cement $^{\circledast}$. Já o cimento Enforce ${ }^{\circledR}$ não apresentou nenhuma ação antibacteriana sobre os micro-organismos do biofilme dental.

Palavras-chave: Cimentos dentários. Biofilmes. Streptococcus. Lactobacillus.

\section{Introdução}

Em prótese fixa, a cimentação é considerada uma das fases mais importantes, o que tem motivado pesquisadores a buscarem materiais estéticos biocompatíveis com propriedades mecânicas favoráveis e resistentes às agressões da cavidade bucal.

Um agente ideal da cimentação deveria ser resistente à penetração de micro-organismos, uma vez que a infiltração de bactérias na interface dente/cimento/restauração está diretamente relacionada às cáries secundárias, com as diversas respostas pulpares e, consequentemente, com a redução da longevidade da restauração. A capacidade de destruir micro-organismos patogênicos ou inibir seu crescimento assume um valor fundamental na função dos cimentos, embora o crescimento bacteriano sob próteses ou restaurações indiretas possa ou não causar injúria pulpar ${ }^{1-3}$.

Os cimentos resinosos são os agentes cimentantes indicados para cimentação de vários tipos de restaurações estéticas, como próteses fixas, inlay, onlay, facetas ${ }^{4}$; devido à sua adesividade a diferentes substratos, à alta resistência, à insolubilidade em ambiente oral e, também, à sua variabilidade de cores $^{4}$. Nas restaurações indiretas estéticas, a adesão resinosa fornece uma retenção superior aos cimentos convencionais, como também há evidências de que

Doutora em Odontologia Restauradora - especialidade Prótese Dentária. Departamento de Prótese Dentária Instituto de Ciência e Tecnologia, Universidade Estadual Paulista Júlio de Mesquita Filho, São José dos Campos, SP, Brasil.

Professora doutora da Escola Técnica de Saúde, Universidade Federal da Paraíba, João Pessoa, PB, Brasil

Professora associada I, Departamento de Clínica Odontológica e Social, Universidade Federal da Paraíba, João Pessoa,PB, Brasil.

Cirurgiã-dentista, Universidade Federal da Paraíba, João Pessoa, PB, Brasil.

Professora adjunta IV, Departamento de Biologia Molecular, Universidade Federal da Paraíba, João Pessoa, PB, Brasil. 
o uso de cimentos resinosos em coroas de cerâmica pura tem aumentado a sua resistência à fratura ${ }^{5-7}$.

$\mathrm{O}$ presente estudo objetivou analisar a ação antibacteriana de cimentos resinosos sobre micro-organismos do biofilme dental. A hipótese nula a ser testada é a de que nenhum dos cimentos resinosos testados apresenta atividade antibacteriana sobre os micro-organismos do biofilme dental; já a hipótese alternativa adotada é a de que os cimentos resinosos testados apresentam atividade antibacteriana sobre os micro-organismos do biofilme dental.

\section{Materiais e método}

Para o presente estudo, foram selecionados três cimentos adesivos resinosos de dupla polimerização (dual cure), apresentados na Tabela 1.

Tabela 1 -Cimentos adesivos resinosos utilizados no estudo, conforme o nome comercial, a composição e o fabricante

\begin{tabular}{|c|c|c|}
\hline Nome comercial & Composição & Fabricante \\
\hline Panavia $^{\circledR}$ F2.0 & $\begin{array}{l}\text { Pasta A: dimetacrilatos hidrófobos e hidrófilos, 10-MDP, sílica coloidal, } \\
\text { sílica silanizada, canforoquinona, peróxido de benzoíla. } \\
\text { Pasta B: dimetacrilatos hidrófobos e hidrófilos, vidro de bário silanizado, } \\
\text { óxido de titânio silanizado, fluoreto de sódio, sílica coloidal, sal sulfinato de } \\
\text { sódio benzênico } 2,4,6 \text { triisopropil, n, n-dietanol p- toluidina e pigmentos. }\end{array}$ & $\begin{array}{l}\text { Kuraray Medical Inc., } \\
\text { Okayama, Japão }\end{array}$ \\
\hline $\begin{array}{l}\text { Fill Magic Dual } \\
\text { Cement }^{\circledR}\end{array}$ & $\begin{array}{l}\text { Pasta base: monômero e metacrilato. } \\
\text { Pasta catalizadora: monômero e metacrilato. }\end{array}$ & $\begin{array}{l}\text { Vigodent, } \\
\text { Bonsucesso, Brasil }\end{array}$ \\
\hline Enforce $^{\circledR}$ & $\begin{array}{l}\text { Pasta base: TEGDMA, vidro de boro, silicato de alumínio e bário silanizado, } \\
\text { sílica pirolítica silanizada, cânforoquinona, EDAB, BHT, pigmentos } \\
\text { minerais, DHEPT. } \\
\text { Pasta catalisadora: dióxido de titânio, sílica pirolítica silanizada, pigmentos } \\
\text { minerais, Bis-GMA, BHT, EDAB TEGDMA, peróxido de benzoíla. }\end{array}$ & $\begin{array}{c}\text { Dentisply, Petrópolis, } \\
\text { Brasil }\end{array}$ \\
\hline
\end{tabular}

Fonte: elaborado pelos autores.

Os cimentos foram analisados logo após a manipulação (estado fresco) e após a presa (fotopolimerizado) sobre as linhagens bacterianas Streptococcus mutans (ATCC 25175), Streptococcus sanguis (ATCC 10557), Streptococcus sobrinus (ATCC 27609) e Lactobacillus casei (ATCC 7469).

O método utilizado para a confecção dos corpos de prova dos cimentos foi semelhante a um método empregado na literatura ${ }^{8}$. Foram confeccionados 48 corpos de prova, com $2 \mathrm{~mm}$ de altura e $6 \mathrm{~mm}$ de diâmetro para a análise dos cimentos no estado fotopolimerizado. Para isso, foram utilizados 48 tubetes de vidro de anestésico infiltrativo local como molde para a inserção dos cimentos. Os tubetes foram esvaziados, limpos e esterilizados em autoclave. Em seguida, removeu-se o lacre metálico do tubete e o êmbolo foi empurrado para a outra extremidade, deixando-se apenas $2 \mathrm{~mm}$ de altura para posterior inserção do cimento. Cada cimento foi manipulado de acordo com as instruções dos respectivos fabricantes e inserido na extremidade do tubete e fotopolimerizado. Para a obtenção dos corpos de prova, o êmbolo foi empurrado e o corpo-de-prova foi expelido do interior do tubete.

A atividade antibacteriana foi determinada pelo método de difusão em ágar em meio sólido ${ }^{9}$. Para tanto, utilizou-se o meio de cultura Ágar Mueller Hinton (MH) (Difco Laboratories Inc., Detroit, Michigan, EUA), que é empregado para testes de suscetibilidade antimicrobiana. As linhagens bacterianas foram cultivadas em caldo nutritivo Brain Heart Infusion (BHI) (Difco Laboratories Inc., Detroit, Michigan, EUA) e incubadas a $37^{\circ} \mathrm{C}$ por 18 a 20 horas em microaerofilia, pelo método da chama da vela. A análise foi feita por meio da técnica do poço e da superfície, cujo ensaio foi realizado em duplicata a cada linhagem bacteriana estudada.

Na técnica do poço, foram realizadas perfurações de $6 \mathrm{~mm}$ de diâmetro no meio de cultura, respeitando a distância de $2 \mathrm{~cm}$ entre os poços, garantindo, assim, a não interferência entre os halos produzidos no meio de cultura. Em seguida, os cimentos foram depositados no estado fresco e no estado fotopolimerizado (corpo de prova) no interior dos poços. Em relação à técnica da superfície, cada cimento foi depositado sobre a superfície do meio de cultura no estado fresco e no estado fotopolimerizado.

Após o período de 24 horas de incubação, foi realizada a leitura dos halos de inibição por meio de régua milimetrada. Dessa forma, foi considerado como halo de inibição quando o diâmetro era igual ou superior a $12 \mathrm{~mm}$; quando o halo apresentava diâmetro menor que $12 \mathrm{~mm}$, foi considerado ausência de halo de inibição.

Os dados obtidos foram transferidos para o programa estatístico Statistical Package for the Social Sciences (SPSS) - versão 13.0 (IBM Company, Chicago, Illinois, EUA). A avaliação sobre normalidade amostral foi conduzida pelo teste Kolmogorov-Smirnov e teste de Levene, para verificar a igualdade de variâncias para comparação de duas amostras independentes. $O$ teste $t$ de Student foi adotado para duas amostras emparelhadas, e para a confirmação dos resultados, o teste de associação de Qui-Quadrado, adotando um nível de significância de $5 \%$. 


\section{Resulltados}

De acordo com a Tabela 2, o cimento Panavia ${ }^{\circledR}$ F2.0 produziu maiores médias de halos de inibição sobre as linhagens bacterianas, seguido pelo cimen- to Fill Magic Dual Cement ${ }^{\circledR}$. No entanto, o cimento Enforce ${ }^{\circledR}$ não produziu halo de inibição sobre nenhuma linhagem bacteriana estudada, independente do estado utilizado ou da técnica empregada.

Tabela 2 -Média (mm) dos halos de inibição sobre as linhagens bacterianas de acordo com o cimento, o estado e a técnica utilizada

\begin{tabular}{|c|c|c|c|c|c|c|}
\hline \multirow{2}{*}{ Cimento } & \multirow{2}{*}{ Técnica } & \multirow{2}{*}{ Estado } & \multicolumn{4}{|c|}{ Linhagens bacterianas } \\
\hline & & & S. mutans & S. sobrinus & S. sanguis & L.casei \\
\hline \multirow{4}{*}{ Fill Magic Dual Cement ${ }^{\circledR}$} & \multirow{2}{*}{ Superfície } & Fresco & 16 & 18 & 17,5 & 14 \\
\hline & & Foto & 0 & 0 & 0 & 0 \\
\hline & \multirow{2}{*}{ Poços } & Fresco & 13 & 14,5 & 15 & 15 \\
\hline & & Foto & 0 & 0 & 12 & 12 \\
\hline \multirow{4}{*}{ Enforce $^{\circledR}$} & \multirow{2}{*}{ Superfície } & Fresco & 0 & 0 & 0 & 0 \\
\hline & & Foto & 0 & 0 & 0 & 0 \\
\hline & \multirow{2}{*}{ Poços } & Fresco & 0 & 0 & 0 & 0 \\
\hline & & Foto & 0 & 0 & 0 & 0 \\
\hline \multirow{4}{*}{ Panavia ${ }^{\circledR}$ F2.0 } & \multirow{2}{*}{ Superfície } & Fresco & 19 & 16,5 & 18,5 & 21 \\
\hline & & Foto & 14,5 & 12 & 14,5 & 12 \\
\hline & \multirow{2}{*}{ Poços } & Fresco & 17,5 & 18,5 & 19,5 & 19 \\
\hline & & Foto & 17,5 & 17 & 21,5 & 0 \\
\hline
\end{tabular}

Fonte: elaborado pelos autores.

Quanto à influência da técnica na produção de halos de inibição pelos cimentos, verificou-se que não houve diferença estatisticamente significativa (teste $t$ de Student p-valor $>0,05$ ) entre a técnica da superfície e a técnica de poços (Tabela 3 ).

Tabela 3 - Teste de associação Qui-Quadrado entre as técnicas empregadas no estudo

\begin{tabular}{|c|c|c|c|c|c|c|}
\hline \multirow{3}{*}{ Linhagens bacterianas } & \multicolumn{4}{|c|}{ Técnicas } & \multicolumn{2}{|c|}{ Teste exato de Fisher } \\
\hline & \multicolumn{2}{|c|}{ Superfície } & \multicolumn{2}{|c|}{ Poço } & \multirow{2}{*}{$\begin{array}{c}\text { Qui-Quadrado } \\
\text { g.l = } 1\end{array}$} & \multirow{2}{*}{$\begin{array}{c}\text { Significância } \\
\text { p-valor }\end{array}$} \\
\hline & $\mathrm{n}$ & $\%$ & $\mathrm{n}$ & $\%$ & & \\
\hline S. mutans & 2 & 40 & 3 & 60 & 0,533 & $0,500^{*}$ \\
\hline S. sobrinus & 3 & 50 & 3 & 50 & 0,000 & $0,786^{*}$ \\
\hline S. sanguis & 3 & 42,9 & 4 & 57,1 & 1,143 & $0,500^{*}$ \\
\hline L. casei & 3 & 50 & 3 & 50 & 0,000 & $0,786^{*}$ \\
\hline
\end{tabular}

* diferença estatisticamente não significativa

Fonte: elaborado pelos autores.

Em relação à influência do estado dos cimentos na produção dos halos de inibição, os cimentos no estado fresco apresentaram maiores médias de ha- los de inibição sobre as linhagens bacterianas, independente da técnica empregada (Tabela 4). 
Tabela 4 - Medidas ( $\mathrm{mm}$ ) dos halos de inibição produzidos pelos cimentos de acordo com o estado e a técnica empregada

\begin{tabular}{|c|c|c|c|c|c|c|c|c|}
\hline \multirow{3}{*}{$\begin{array}{l}\text { Linhagens bacterianas } \\
\text { (duplicata) }\end{array}$} & \multicolumn{4}{|c|}{ Panavia $^{\top M}$ F2.0 } & \multicolumn{4}{|c|}{ Fill Magic Dual Cement $®$} \\
\hline & \multicolumn{2}{|c|}{ Superfície } & \multicolumn{2}{|c|}{ Poços } & \multicolumn{2}{|c|}{ Superfície } & \multicolumn{2}{|c|}{ Poços } \\
\hline & Fresco & Foto. & Fresco & Foto. & Fresco & Foto. & Fresco & Foto. \\
\hline S. mutans & 18 & 16 & 17 & 18 & 17 & 0 & 14 & 0 \\
\hline S. mutans & 20 & 13 & 18 & 17 & 15 & 0 & 12 & 0 \\
\hline S. sobrinus & 16 & 12 & 18 & 20 & 17 & 0 & 15 & 0 \\
\hline S. sobrinus & 17 & 12 & 19 & 14 & 19 & 0 & 14 & 0 \\
\hline S. sanguis & 17 & 15 & 19 & 22 & 15 & 0 & 15 & 12 \\
\hline S. sanguis & 20 & 14 & 20 & 21 & 20 & 0 & 15 & 12 \\
\hline L. casei & 20 & 12 & 18 & 0 & 13 & 0 & 15 & 12 \\
\hline L. casei & 22 & 12 & 20 & 0 & 15 & 0 & 15 & 12 \\
\hline Média & 18,75 & 13,25 & 18,63 & 14,00 & 16,38 & 0,00 & 14,38 & 6,00 \\
\hline
\end{tabular}

Fonte: elaborado pelos autores.

O Streptococcus sanguis foi a linhagem que apresentou maior sensibilidade, independente do estado do cimento ou da técnica empregada.

\section{Discussão}

A discussão desta pesquisa foi fundamentada em estudos que investigaram a ação antimicrobiana sobre cimentos odontológicos, uma vez que há inúmeros artigos que tratam da temática, focando principalmente nos cimentos endodônticos e de ionômero de vidro, porém poucas publicações sobre os cimentos resinosos utilizados em restaurações protéticas, Desse modo, o presente estudo torna-se extremamente importante para a comunidade odontológica, tendo-se em vista que a cárie secundária é um dos principais fatores de insucesso das restaurações protéticas ${ }^{10}$.

Dos cimentos avaliados, Panavia ${ }^{\circledR}$ F2.0 foi o que apresentou maior ação antibacteriana sobre os micro-organismos do biofilme dental, independente do estado ou da técnica empregada no estudo. O cimento Enforce® não apresentou ação antibacteriana sobre nenhuma das linhagens bacterianas estudadas, sendo este resultado semelhante ao trabalho previamente publicado ${ }^{11}$, que avaliou a atividade antibacteriana de agentes cimentantes sobre $S$. mutans, S. pyogenes, S. aureus, E. faecalis e E. coli, constatando que esse cimento não tinha ação antibacteriana sobre nenhum micro-organismo testado.

As diferenças observadas na ação antibacteriana de materiais verificadas em testes de difusão em ágar podem estar ligadas a diversos fatores, como: os elementos da composição química dos materiais; o acréscimo intencional de substâncias antimicrobianas; o $\mathrm{pH}$ dos diversos materiais; a difusibilidade dos íons ou pequenas moléculas; a grande quantidade de flúor liberado e partículas de prata ${ }^{12-14}$.

Os cimentos resinosos no estado fresco apresentaram maiores halos de inibição sobre as linhagens bacterianas testadas. Os achados desta pesquisa concordam com estudo anterior ${ }^{15}$, que observou que cimentos resinosos, após a presa, tinham a sua atividade antimicrobiana diminuída ou perdida.

No presente estudo, as técnicas de poços e de superfície apresentaram eficiências equivalentes na produção de halos sobre os micro-organismos do biofilme dental. No entanto, a utilização da técnica do poço e a deposição do cimento no estado fresco no interior dos poços proporcionam uma maior superfície de contato e, consequentemente, uma maior difusão no meio ágar, quando comparadas com a colocação de amostras de cimento, após a sua polimerização sobre a superfície do meio de cultura ${ }^{16}$.

A linhagem bacteriana mais sensível aos cimentos analisados foi Streptococcus sanguis, o que difere de resultados encontrados na literatura ${ }^{17}$, segundo os quais, as linhagens bacterianas $S$. mutans e $S$. sanguis apresentam sensibilidade análogas aos cimentos de ionômero de vidro. No entanto, outra pesquisa constata que as linhagens bacterianas $S$. mutans e $S$. sanguis foram totalmente resistentes aos cimentos de ionômero de vidro restauradores avaliados ${ }^{18}$.

A hipótese nula a ser testada foi refutada, aceitando-se a hipótese alternativa de que os cimentos resinosos testados apresentam ação antimicrobiana sobre os micro-organismos do biofilme dental, com exceção do cimento Enforce ${ }^{\circledR}$, que não apresentou atividade antimicrobiana. Assim, considera-se de suma importância o papel da atividade antibacteriana dos cimentos resinosos, e sugere-se que o conhecimento minucioso dessa propriedade pelo cirurgião-dentista deve ser um dos critérios de escolha do agente cimentante em reabilitação oral, uma vez que é indispensável à preservação da saúde dental e periodontal, promovendo uma maior longevidade à restauração.

Estudos futuros devem ser realizados com ensaios mais detalhados que contemplem o envelhecimento da amostra e com amostras mais complexas, como coroas, facetas e incrustações a serem cimentadas sobre um preparo dental ou retentor intrarradicular para, assim, avaliar com uma maior aproximação clínica a ação antimicrobiana de cimentos resinosos sobre o biofilme dental. 


\section{Conclusão}

Considerando-se a metodologia empregada e os resultados obtidos neste estudo, pôde-se concluir que o cimento Panavia ${ }^{\circledR}$ F2.0 foi o que apresentou maior ação antibacteriana, seguido do Fill Magic Dual Cement ${ }^{\circledR} . \mathrm{O}$ cimento Enforce ${ }^{\circledR}$ não apresentou nenhuma ação antibacteriana sobre os micro-organismos do biofilme dental.

\section{Agradecimentos}

À Coordenação de Aperfeiçoamento de Pessoal de Nível Superior pelo financiamento da investigação. À Dentisply (Brasil), pelo fornecimento do cimento resinoso Enforce ${ }^{\circledR}$ utilizado no estudo.

\section{Abstract}

Objective: This study aimed to examine the antibacterial action of dual-curing resin cements on microorganisms of dental biofilm. Materials and method: Three resin cements were selected (Panavia ${ }^{\text {TM }}$ F2.O, Fill Magic Dual Cement $^{T M}$, and Enforce $\left.{ }^{T M}\right)$, as well as bacterial strains of Streptococcus mutans, Streptococcus sanguis, Streptococcus sobrinus, and Lactobacillus casei. Through the well and surface techniques, the agar diffusion test was used with light-cured and fresh cements. After 24 hours of incubation, readings of inhibition halos were taken. Results: The Panavia ${ }^{\text {TM }}$ F2.0 produced inhibition halos on all bacterial strains, regardless of the state or technique applied. The Fill Magic Dual Cement ${ }^{T M}$, when fresh, presented antibacterial action on all strains studied, however, when light-cured, it produced antibacterial action only on strains of $S$. sanguis and L. casei. On the other hand, the resin cement Enforce ${ }^{\text {TM }}$ did not produce halos on any bacterial strain. Conclusion: Panavia ${ }^{T M} \mathrm{~F} 2.0$ was the resin cement with the highest antibacterial action, followed by Fill Magic Dual Cement ${ }^{\text {TM }}$. However, the Enforce ${ }^{T M}$ cement showed no antibacterial action on microorganisms of dental biofilm.

Keywords: Dental cements. Biofilms. Streptococcus. Lactobacillus.

\section{Referências}

1. Kidd EA, Beighton D. Prediction of secondary caries around tooth colored restorations: a clinical microbiological study. J Dent Res 1996; 75:1942-46.

2. Forss H. Release of fluoride and other elements from light-cured glass ionomers in neutral and acidic conditions. J Dent Res 1993; 72(8):1257-62.

3. Tobias RS. Antibacterial properties of dental restorative materials: a review. Int Endod J 1988; 21:155-60.

4. Bandini SR, Tavares ACS, Guerra MAL, Dias NF, Vieira CD. Cimentação adesiva - revisão de literatura. Rev Odonto 2008; 16(32):105-15.

5. Hofmann N, Papsthart G, Hugo B, Klaibar B. Comparison of photo-activation versus chemical or dual-curing of resin- -based luting cements regarding flexural strength, modulus and surface hardness. J Oral Rehabil 2001; 28(11):1022-8.

6. Van Dijiken JWV. Restorations with extensive dentón/enamel-bonded ceramic coverage: a 5 - year follow-up. Eur $\mathrm{j}$ Oral Sci 2001; 109(4):222-9.

7. Makkar S, Malhotra N. Self-adhesive resin cements: a new perspective in luting technology. Dent Update 2013; 40(9):758-68.

8. Aun JC, Alberto LHBF, Badini SRG, Ferreira DRP, Pousada OALL. Avaliação da capacidade inibitória de crescimento de $S$. mutans de diferentes materiais restauradores. Rev Odonto 2005 ; $13(25): 34-41$.

9. Bauer AW, Kirby WMM, Sherris JC, Turck M. Antibiotic susceptibility testing by a standardized single disk method. Am J Clin Pathol 1966; 45:493-6.

10. Ozkurt Z, Kazazoğlu E. Clinical success of zirconia in dental applications. J Prosthodont 2010; 19(1):64-8.

11. Pereira DC, Afonso TS, Chavasco JK. Estudo in vitro da ação antimicrobiana de agentes cimentantes utilizados em Odontologia sobre Streptococcus mutans, Streptococcus pyogenes, Staphylococcus aureus, Enterococcus faecalis e Escharichia coli. Rev Univ Alfenas 1998; 41:175-8.

12. Afonso TS, Pizzolito AC. Avaliação in vitro da ação antibacteriana de materiais restauradores posteriores sobre o micro-organismo S. mutans. Rev Esc Farm Odontol Alfenas 2000; $22: 10-3$.

13. Damasceno FMB, Moreira EJ, Abad EC. Estudo comparativo da atividade antifúngica de cimentos endodônticos e do agregado de trióxido mineral (MTA). Rev Bras Odontol 2008; 65(1):66-71.

14. Rodrigues RCV, Soares RG, Silva TM, Marotta OS, Kill KB, Duailibe SAC et al. Atividade antimicrobiana de diferentes cimentos endodônticos. Rev Bras Pesqui Saúde 2012; 14(3):34-7.

15. Tobias RS, Browne RM, Wilson CA. Antibacterial activity of dental restorative materials. Int Endod J 1985; 18:161-71.

16. Tobias RS. Antibacterial properties of dental restorative materials: a review. Int Endod J 1988; 21:155-60.

17. Afonso TS, Adabo GL, Pizzolito AC. In vitro study of the antimicrobial action of dentin-pulp complex protector cements on S. mutans and S. sanguis. Rev Odontol Unesp 1995; 24(2):317-26

18. Sander HH, Janser WC, Santos VR. Análise in vitro da atividade antibacteriana de cimentos de ionômero de vidro restauradores sobre Streptococccus mutans e Streptococccus sanguis. Arq Odontol 2002; 38(1):1-81.

\section{Endereço para correspondência:}

Viviane Maria Gonçalves de Figueiredo

Praça João Pessoa, no 16 a - Centro

58297-000 Rio Tinto, Paraíba, Brasil

Telefone: 83999860812

E-mail: vivi_mfigeiredo@yahoo.com.br

Recebido: 26/11/14. Aceito: 12/08/15. 